Stein, J. A., Feige, Y., and Hochman, A. (1957). J. Lab. clin. Med., Tata, $\mathbf{j}$. R.

, R., Rall, J. E., and Rawson, R. W. (1956). J. clin. Endocr., 16 1554.

. Jaimet, C. H. and Kirkwood, S. (1954). Radioisotope Conference, 1954, Oxford, 1, 55. Butterworth, London.

Werner, S. C. Block, R. J., Mardl. R. H., and Kassenaar, A. A. H. (1957). J. clin: Endocr. 17, 817

Whitelaw, M. J. Thomas, S., and Reilly, W. A. (1956). Ibid., 16, 983. Zondek, H. (1918). Münch. med. Wschr., 65, 1180.

(1919). Ibid. 66, 681.

(1923). Die Krankheiten der endokrinen Drüsen, p. 221 f. Springer, Berlin

Dtsch, med. Wschr. 1, 364

(1953). Die Krankheiten der endokrinen Drïsen, new ed., D. 549.

Leszynsky, H. E., and Zondek, G. W. (1955). Acta endocr. (Kbh.), 18, 117.

\section{CARDIOMYOTOMY FOR ACHALASIA OF THE CARDIA}

THE EXPERIENCE OF THE MIDDLESEX

AND HAREFIELD HOSPITALS UP TO 1955

BY

E. D. ACHESON, $\underset{\text { Medical Registrar }}{\text { Reg. M.R.C.P. }}$

AND

G. D. HADLEY, M.D., F.R.C.P. Assistant Physician

From the Institute of Clinical Research, Middlesex Hospital

Although cardiomyotomy for achalasia of the cardia was described by Heller in 1914 it was not widely practised in Britain or America until 30 years later. Writing from the Mayo Clinic in 1940, Gray and Skinner reported that Heller's operation had not been used in the treatment of 1,200 cases of achalasia seen there up to that time. Grey Turner (1946) did not recommend cardiomyotomy for achalasia.

The first report of the successful use of cardiomyotomy in this country came from Barlow (1942), who described four operations. Barrett (1950) and Allison (1950) advocated Heller's operation as the surgical treatment of choice. Several further papers (Wangensteen, 1951 ; Effler and Rogers, 1955 ; Brewer et al., 1956) confirmed Barrett's opinion that Heller's operation should replace the more radical operations because it is not followed by peptic oesophagitis. Other recent evidence, however, has suggested that Heller's operation may also be followed by the symptoms and complications of gastro-oesophageal reflux (Hawthorne and Nemir, 1953; Hawthorne et al., 1956).

This paper is an attempt to cast further light on the value and limitations of cardiomyotomy and the incidence of post-operative peptic oesophagitis by reviewing the combined experience of the surgeons of the Middlesex and Harefield Hospitals from its introduction in 1947 until 1955. The results have been assessed by physicians who have not been concerned in the treatment of most of the patients.

\section{Material}

Cardiomyotomy was performed on 26 patients at the Middlesex Hospital and nine patients at Harefield Hospital between April, 1947, and August, 1955. Between May, 1956, and March, 1957, 27 of these were interviewed, examined, and weighed by one of us (E. D. A.), and a barium swallow examination was made of each. Of the remainder, two are dead, four could not be traced, one was too disabled by chronic lung disease to leave her home, and one lived at too great a distance to attend for examina- tion. We have incolmplete information about the present health of the latter two patients from their family doctors. Of the four who were untraced, two attended the outpatient department for 19 and 20 months after operation respectively. The other two patients have not been heard of since leaving hospital. The two patients who died attended hospital until shortly before their deaths.

Thus we have complete data in 27 cases, incomplete information in a further six, and no information about two patients (Table I).

TABLE I.-Material

$\begin{array}{lllllllll}\text { No. interviewed } & \ldots & \ldots & \end{array}$

Traced, but unable to attend (information from family doctors) $\ldots \quad \ldots \quad 2$ Untraced:

Some information

No information

Eight patients were male and 27 female, and the average age of the group at operation was 45 years. The average duration of symptoms before operation was 10 years 5 months (range 1 to 51 years). Nineteen of the 35 patients in the series had received previous treatment with Hurst's mercury bougies, with the Negus hydrostatic bag, or had undergone oesophagoscopy and dilatation. In 17 of these the pre-operative treatment had been given a fair trial and had failed. In one case dilatation through an oesophagoscope and in another dilatation with a Negus bag had been performed within the fortnight immediately before the operation; there had been no other previous treatment. In three other cases octyl nitrite had been taken with temporary benefit. In the remaining 13 cases there is no evidence of any treatment having been given before cardiomyotomy was performed.

The mean period which elapsed between the date of operation and the date of interview was 3 years 10 months. Fig. 1 shows the distribution of the cases from this point of view.

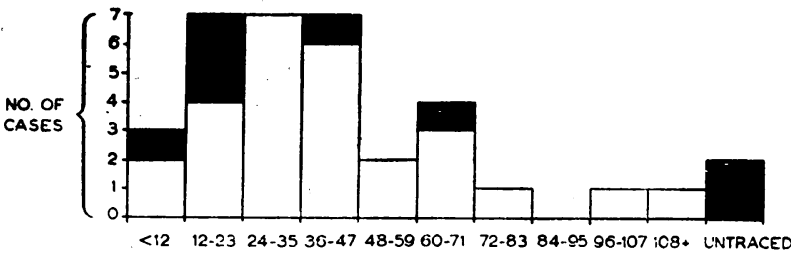
FOLLOW-UP PERIOD IN MONTHS

Fig. 1.-Length of time from operation to interview. Cases not interviewed are shown in black.

Associated Conditions.-Fourteen patients (40\%) gave a history of respiratory infection. In $4(11 \%)$ there was evidence of rheumatoid arthritis. This supports the impression of Allison (1950) and Wooler (1948) that there may be an association between rheumatoid arthritis and achalasia of the cardia.

\section{The Operation}

Seven different surgeons performed the 35 operations in the series; four were thoracic and three general surgeons. The thoracic surgeons performed 17 operations, of which 13 were successful, and the general surgeons 18, of which 15 were successful. The cardia was approached through the thorax in 22 cases and from the abdomen in 3 . In 10 cases the incision involved both thorax and abdomen. In each case a single longitudinal incision was made in the oesophagus down to the submucosa. The length of the incision was recorded in the operation notes in 27 of the 35 cases. It varied from $1 \frac{1}{2}$ to 6 in. $(3.8$ to $15 \mathrm{~cm}$.), mean 3.1 in. $(7.87 \mathrm{~cm}$.). Information concerning the extension of the cut on to the wall of the stomach was incomplete. In this series no correlation has been found between the length of the.cut in the oesophageal wall, as recorded in the operation notes, and the clinical success of the operation. However, in view of the doubt about the methods used for the measurement of the incision at operation, it would be unwise to draw definite conclusions. 


\section{Results}

If the two untraced patients are excluded there remain 33 cases for analysis. The operative mortality was nil. Two patients died of coronary occlusion 7 and 13 months after the operation respectively.

An operation was regarded as having failed if further mechanical treatment was required at a later date to relieve dysphagia. This occurred in seven patients $(21 \%)$. Details of these are discussed below.

The success of cardiomyotomy in the remaining patients has been assessed on the following criteria: (1) The patient's answer to the question, What do you think of the operation? (2) On the basis of the patient's symptoms at the time of interview. If necessary, direct questions were asked to ascertain the presence or otherwise of old symptoms (for example, dysphagia) and new symptoms (for example, heartburn). Our assessment did not always correspond with the patient's. (3) Change in body weight since the operation. (4) Change in radiological findings.

\section{Comparison of Assessments}

Patients' Assessment.-Twenty-seven patients were asked their opinion of the operation. Three replied that it had restored them to perfect health, 13 were " much better," and 5 others "better." The remaining 6 had required further mechanical treatment. Thus 21 out of 27 patients interviewed considered that they had gained benefit in some degree from the operation.

Our Assessment.-This was based on the patient's answers to questions about the following individual symptoms: dysphagia, regurgitation of food, diet, time taken over meals, chest pain, heartburn, acid regurgitation, use of nitrites and antacids. Our standards were higher than were the patients'. We defined as "cured" a patient who denied all the symptoms for which the operation had been performed and who had no fresh symptoms attributable to the operation. Thus of the three patients who were "cured" according to their own assessment only one had no symptoms. One remains the last in the family to finish her food, still requires to drink water to help to swallow solids, and requires a supply of antacids at her bedside to combat heartburn. The other patient experiences occasional heartburn only. We classified as " much better" any patient who experienced dysphagia or regurgitation less than once a fortnight, and who did not require to take antacids for heartburn. Five patients are in this category. Fourteen patients who have improved as a result of the operation, but who still experience dysphagia or regurgitation at least once a fortnight or who require antacids, have been classified by us as " better."

One patient who considered herself to be "better but deteriorating" was, by our standards, no better than before operation. She experiences dysphagia daily and requires frequent drinks of water during meals. Although she has not regurgitated food since her operation, she is disturbed almost every night by heartburn, and has to get out of bed and take bicarbonate of soda.

The manifest difference (Table II) between the patients' assessment of the merits of the operation and ours is probably due to the fact that we have used the symptomfree person as our yardstick, while many of the patients have had oesophageal obstruction for so long that they have

TABLE II.-Assessments Compared

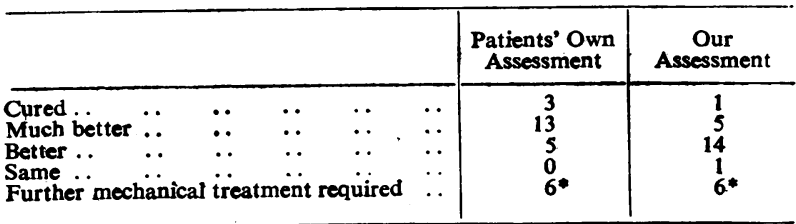

- The seventh patient in this group was not interviewed, and is excluded from this analysis. forgotten what it feels like to be normal. Their yardstick is their state before operation, and they are quick to acknowledge any improvement in strong terms.

\section{Effect of Cardiomyotomy on Individual Symptoms}

This analysis is based on those patients who had been interviewed and who had not required post-operative mechanical treatment (a total of 21 cases).

Regurgitation of Food.-From the patient's point of view this is the most embarrassing symptom of achalasia of the cardia. Its presence frequently makes the patient eat as a recluse. In the present series cardiomyotomy has improved regurgitation in all cases classified as successful. In 11 cases it has been absent since operation, and in a further seven it is occasional-that is, twice a year or less. In only three has regurgitation of food been troublesome, in two it occurs once a month, ahd in one once a fortnight.

Dysphagia.-This has been less effectively relieved. It is absent in three cases, occurs less often than once a fortnight in eight, but is frequent and troublesome in 10.

Time Taken Over Meals.-Patients with achalasia characteristically are last at the table to finish their meals. In this series this symptom had been invariable prior to operation. In 10 it was relieved by surgery, but the remaining 11 admitted that they still took an abnormally long time to eat a meal, although less than previously.

\section{Appearance of New Symptoms After Cardiomyotomy}

It is widely recognized that regurgitation of peptic juice into the gullet is a hazard of operations which disturb the mechanism of the cardia. Thus cardioplasty and cardiectomy are now seldom practised because they are followed by peptic ulcer of the oesophagus with haemorrhage and stricture formation in a very large proportion of cases (Barrett and Franklin, 1949 ; Wangensteen, 1951 ; Effler and Rogers, 1955; Brewer, et al., 1956). On the other hand, it has been widely held that post-operative peptic oesophagitis rarely follows cardiomyotomy (Barrett, 1950; Michaud and Latreille, 1955). However, Hawthorne and Nemir (1953) found radiological evidence of gastro-oesophageal regurgitation following cardiomyotomy in half their patients.

In this series it was unfortunately impossible to examine the patients in the Trendelenburg position to determine the presence or otherwise of gastro-oesophageal regurgitation. However, a clinical survey has been carried out to discover the incidence of heartburn, anaemia due to oesophageal bleeding, and peptic oesophageal stricture formation. Out of 21 patients who have had one cardiomyotomy, and one further patient who has had two operations, 13 have heartburn and 9 have not. (The other five interviewed have had subsequent surgery other than cardiomyotomy and are not included here.) In two cases heartburn was present preoperatively but it has become worse. Of those with heartburn, eight require to take antacids, and three of these describe it as "very troublesome." All, however, regard their new symptoms as preferable to the old. One patient brings up "a fluid like chocolate" three or four times a year but is not anaemic. Another, who also has severe heartburn, has had several attacks of melaena which, in the absence of any other evident cause, have been ascribed to oesophagitis. An oesophagoscopy 11 months after operation confirmed this diagnosis. She has required continuous treatment with iron since 1954 . In one additional case (classified as a failure) the development of a fibrous stricture 1 in. $(2.5 \mathrm{~cm}$.) above the cardia 2 years 9 months after operation followed a period of oesophagitis with heartburn, melaena, and anaemia.

\section{Change in Body Weight After Operation}

The change in body weight following operation is known in 22 patients other than those who have had recourse to further surgery. The mean change in weight is approximately plus $11 \mathrm{lb}$. $(5 \mathrm{~kg}$.)-range, -14 to $+45 \mathrm{lb}$. $(-6.4$ to $+20.4 \mathrm{~kg}$.). Five out of six patients, classified by us on the 
basis of their symptoms alone as much better or cured, recorded weight gains of $11 \mathrm{lb}$. $(5 \mathrm{~kg}$.) or more; while, conversely, of 10 patients classified as better, three have lost weight and four have made gains less than $11 \mathrm{lb}$. $(5 \mathrm{~kg}$.). There is therefore a rough correlation between symptomatic improvement and weight gain.

No correlation was found between post-operative increase in weight and radiological improvement.

\section{Radiologieal Cbanges}

The absence of a gas bubble in the stomach has been used as a confirmatory radiological sign of achalasia (Johnstone, 1950 ; Franklin, 1952). In this series a small gas bubble was visible in $3(12 \%)$ of 26 cases in which pre-operative firms were available. In two others it was not certain whether the visible gas was in stomach or colon. The largest bubble measured 2 in. $(5 \mathrm{~cm}$.) across (Fig. 2). After operation a gas bubble was present in 17 cases and absent

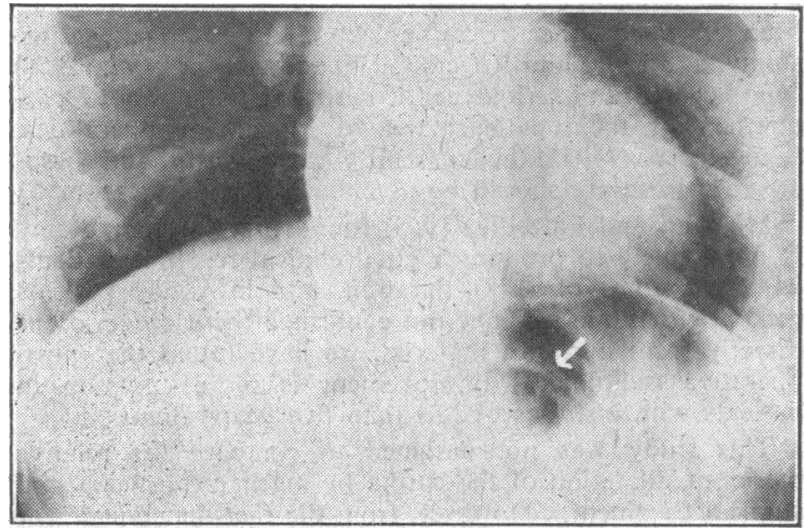

FiG. 2.-Radiograph showing largest bubble.

in 9. The evidence in this series suggests that patients in whom a gas bubble appears in the stomach after operation do better than those in whom it does not.

An enlarged oesophagus was visible to the right of the heart shadow in 10 out of 27 cases before operation. After operation it was no longer visible in six, and still present in three. In the remaining case no information on this point is available.

A barium swallow was performed at the follow-up interview and was compared with pre-operative films. Posterioranterior and left and right anterior oblique views were taken under conditions which were standardized as closely as possible, the patients having first been screened in the erect position. The films were classified by eye, on the bases of degree of dilatation of the oesophagus and delay at the cardia, into the following categories by two independent observers: normal, minimal enlargement, moderate, considerable, severe (all cases with a sigmoid dilatation of the gullet).

As there were wide differences in radiological technique between the pre- and post-operative groups, no comparison was made between the height and width of oesophageal fluid levels. In the circumstances it was felt that the admittedly rough method of comparison by eye would be scarcely less accurate.

Of the 21 successful cases studied, pre-operative films are available in 20 . In 11 the post-operative films show an improvement; in three of these the oesophagus appeared normal. (The pre-operative radiological abnormalities in these three cases had been classified as "considerable" in one and moderate in two.) Complete radiological evidence was also available in all seven unsuccessful cases. In two there had been radiological improvement after the first operation.

An analysis of Table III suggests that, as might be expected, the less prominent the radiological changes before
TABLE III.-Effect of Operation on Radiological Appearances

\begin{tabular}{|c|c|c|c|c|c|c|c|}
\hline \multicolumn{5}{|c|}{ Pro-operative Grading } & \multirow{2}{*}{$\begin{array}{c}\text { Number } \\
6(1) \\
77(4) \\
7 \text { (2) }\end{array}$} & \multirow{2}{*}{$\begin{array}{c}\text { Improved } \\
2 \text { (1) } \\
4 \text { (1) } \\
5 \text { (0) }\end{array}$} & \multirow{2}{*}{$\begin{array}{l}\text { Same } \\
4(0) \\
3 \text { (3) } \\
2 \text { (2) }\end{array}$} \\
\hline $\begin{array}{l}\text { Severe } \\
\text { Considerabje } \\
\text { Moderate .. }\end{array}$ & $\begin{array}{l}. \\
\cdots\end{array}$ & $\begin{array}{l}. . \\
\because .\end{array}$ & $\because$. & $\begin{array}{l}. \\
\because \\
.\end{array}$ & & & \\
\hline & & & Total & .. & $20(7)$ & $11(2)$ & 9 (5) \\
\hline
\end{tabular}

Operative failures in parentheses.

operation, the more likely are they to improve after operation. However, it is notable that in two instances severely dilated gullets diminished in size and tortuosity disappeared.

A further analysis was made to determine whether radiological improvement after operation occurred more often in patients with short pre-operative histories. The mean duration of symptoms in the 12 patients with radiological improvement after operation was 6.1 years; in the nine

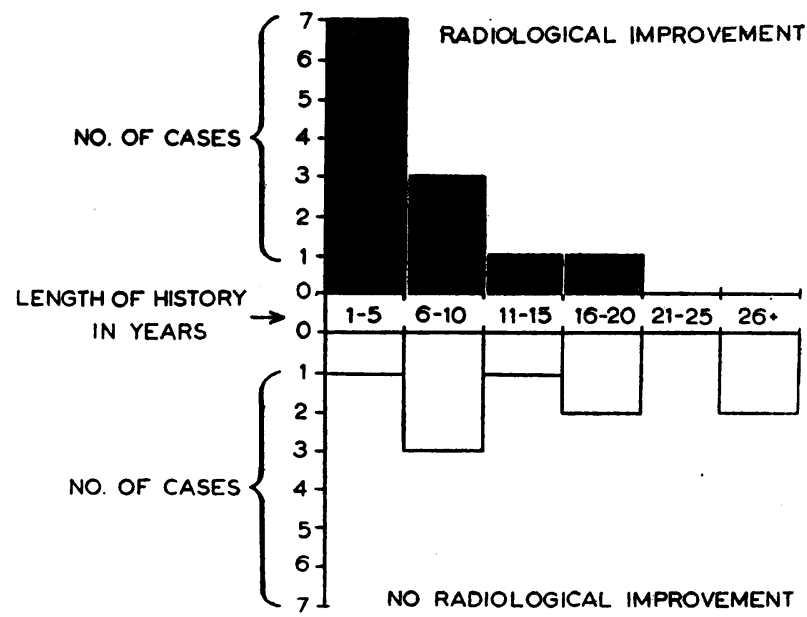

Fro. 3.-Length of history in patients with and without radiological improvement.

patients whose $x$-ray films did not show improvement the mean duration of symptoms was 19.1 years. Fig. 3 shows that 7 of the 12 patients who improved radiologically had pre-operative histories of less than five years, as compared with one of nine patients whose $x$-ray films did not show improvement. These results support the opinion expressed by Allison (1950).

\section{Cases in which Further Surgical Treatment or Bouginage was} Required

Seven of the 31 cases available for analysis required further surgical treatment after cardiomyotomy. In two, cardiomyotomy was repeated, 5 years 10 months and 8 years after the first operation respectively. In one of these perforation of the oesophagus occurred shortly after the second operation, and an oesophago-gastrectomy had to be performed a few days later. One patient still suffers from considerable dysphagia and occasional regurgitation of food 13 months after a second cardiomyotomy. One patient had a recurrence of dysphagia and regurgitation one year after her operation and has returned to daily bouginage. In another case temporary relief of symptoms was followed by a relapse four months after cardiomyotomy, and a cardioplasty was performed seven months later. The radiological appearances remained unchanged and there was no evidence of a traumatic stricture at the second operation.

In one case there was considerable improvement for four years followed by sudden deterioration; 6 years 10 months after her operation this patient was readmitted for oesophagoscopy and a stricture was found at the level of the cardia. This was dilated, but with little symptomatic benefit. It is curious that there had been a striking improvement in the radiological appearance of the oesophagus in this case and that, in spite of her considerable symptoms, barium 
swallow immediately before the dilatation, and subsequently, showed minimal delay at the cardia. This underlines the difficulty in assessment which many of these cases present. In one case a recurrence of the original symptoms also occurred within a few months of operation, and dilatation through an oesophagoscope has been performed on two subsequent occasions. The opinion of the surgeon is that there is now a traumatic stricture at the cardia related to a peri-oesophageal abscess found at operation. However, it is noteworthy that, on screening, the hold-up at the cardia was seen to be released by octyl nitrite. In both these cases, therefore, there seems some doubt whether the return of symptoms is due to a recurrence of achalasia, to a stricture, or to the functional element that is so prominent in many of these patients.

In one case, already mentioned, the immediate postoperative course was stormy and a further thoracotomy was necessary on the fifth day to drain a large clotted pleural effusion. There is a note that the patient complained of heartburn and indigestion before discharge from hospital, and these symptoms subsequently became more troublesome. One year later she was readmitted with a severe irondeficiency anaemia which was attributed to haemorrhagic oesophagitis. At this time, barium regurgitated freely into the gullet in the Trendelenburg position. After a further 18 months in which her heartburn did not abate there was a sudden return of dysphagia. Barium swallow now showed a narrow stricture $2 \mathrm{~cm}$. above the cardia. After several attempts at dilatation through an oesophagoscope, an oesophagogastrectomy was carried out, since when all symptoms have disappeared.

Summarizing the unsuccessful cases, out of seven requiring further mechanical treatment for dysphagia, four showed definite evidence of recurrence of the original condition and two others may fall in the same category, although in neither are the radiological signs commensurate with the symptoms. In one case a stricture resulted from peptic oesophagitis due to reflux of acid from the stomach.

It is interesting that in only one of these seven patients was there any complaint of heartburn or acid eructation after the original operation. This is in striking contrast to the incidence of heartburn in the successful cases. In this group 13 out of 21 patients interviewed $(62 \%)$ admitted that they suffered from heartburn. The appearance of heartburn may prove to be a good rather than a bad prognostic sign, so far as the overall success of the operation is concerned.

A further point of interest in these cases is the length of the interval between operations. In four of the seven cases dysphagia returned after more than two years, and in two of these after more than six years. The average interval was two years six months. This point should be taken into consideration when the early results of cardiomyotomy are being assessed.

There is no material difference between the successful and unsuccessful groups in regard to age, sex, length of history, or severity of radiological changes before operation. Four of the failed cases had received mechanical treatment before their operation and three had not. The proportions are similar in the successful cases. The figures, however, are small, and definite conclusions cannot be drawn from them.

\section{Discussion}

The improvement after cardiomyotomy has been a relative one. Only three patients consider themselves cured, and two of these are not, in fact, completely free of symptoms. The detailed analysis of the symptoms of the remainder may give the impression that they are dissatisfied with the operation. On the contrary, a striking feature of the series has been that, in spite of the appearance in some cases of fresh discomforts attributable to the operation, the patients as a whole have been loud in their praise of cardiomyotomy even when their original symptoms have been incompletely relieved. We feel that this may be due to the relief which the operation almost always affords them from the embar- rassment of regurgitation of food during meals, which permits them to eat in company once again.

Our experience confirms the impression of Hawthorne et al. (1956) that regurgitation of peptic juice is commonly found after cardiomyotomy if sufficiently detailed and prolonged post-operative studies are made. In this respect we appear to differ from Michaud and Latreille (1955), who elicited a history of post-operative chest pain in less than $4 \%$ of their patients. However, when comparing the incidence of heartburn in this series with that of peptic oesophagitis in other publications, it should be recalled that only three $(9 \%)$ of our patients volunteered its presence without direct inquiry, and that in five of the others it requires no treatment and is very infrequent. In most cases it is mild and well tolerated. Only in two cases (6\%) has it led to serious complications, and it is in this respect that this operation compares so favourably with more radical procedures. Thus Barrett and Franklin (1949) found retrosternal pain, haematemesis or melaena, or anaemia due to peptic oesophagitis in as many as 18 of 25 patients who had been subjected either to cardioplasty or to oesophagogastrostomy, and Effler and Rogers (1955) and Brewer et al. (1956) found evidence of serious peptic oesophagitis in about threequarters of their patients treated by similar operations. Wangensteen (1951) believes that cardioplasty and oesophagogastrostomy should be abandoned for this reason.

Michaud and Latreille (1955) found that cardiomyotomy is more likely to produce a good clinical result in patients with symptoms of short duration, and in young patients generally. While we have not confirmed these observations directly from our own material, we have found that postoperative radiological improvement is more common in patients with histories of less than five years' duration.

This study was not designed to compare the relative merits of dilatation of the cardia by mechanical means and surgical treatment. However, from the fact that bougies or hydrostatic bags had already failed to control the disease in 17 cases in this series, it is clear that. at present, surgery has an important place in the treatment of achalasia of the cardia. In our opinion, when surgery is indicated. cardiomyotomy, although imperfect, remains the hest available operation. If symptoms of regurgitation are treated by alkalis and suitahle nocturnal posture as snon as they arise, it may be possible to reduce complications still further.

\section{Summary}

Of 35 patients on whom a cardiomyotomy was performed at the Middlesex and Harefield Hospitals, 29 were interviewed, and incomplete information is available about 6 others. The average follow-up period was 3 years 10 months.

Of 33 patients whose condition in 1956 is known, 2 had died of unrelated disease. 24 consider that they have received benefit, and $7(21 \%)$ have needed further mechanical or surgical treatment for oesophageal obstruction, and are classified as failures. The operative mortality was nil.

Degrees of success have been gauged according to the patients' own testimony, an analysis of symptoms at interview, change in body weight, and improvement in the radiological appearance of the oesophagus. The difficulties in assessment are discussed.

Peptic oesophagitis may follow cardiomyotomy. In this series a peptic stricture occurred in one case, oesophagitis with haemorrhage and anaemia in another, and heartburn which required treatment in six others. With the exception of the first instance these symptoms were well tolerated.

Cardiomyotomy effectively relieved regurgitation of food. It relieved dysphagia and delay over meals less effectively. 
There was no correlation between clinical and radiological improvement in individual cases. The less severe the radiological changes before operation the more likely they were to improve. Radiological improvement occurred more often in patients with a pre-operative history of less than five years than in those with longer histories.

Failure was due to recurrence of achalasia in four cases and peptic stricture in one. In two cases the cause of failure was uncertain. Relapse may occur more than six years after cardiomyotomy.

In spite of its manifest imperfections cardiomyotomy remains the best available surgical operation for achalasia of the cardia.

We thank the surgeons of the Middlesex and Harefield Hospitals who permitted us to study their patients and report these findings.

\section{REFERENCES}

Allison, P. R. (1950). Proc. roy. Soc. Med., 43, 425.

Barlow. D. (1942), Brit. J. Surg, 29, 415.

Barrett, N. R. (1950). Proc. roy. Soc. Med., 43, 421

- and Franklin, R. H. (1949). Brit. J. Surg., 37, 194. Brewer, McH. S., Barnes, W. A., and Redo, S. F. (1956). Ann. Surg., 144.

Effler. D. B.. and Rogers, J. W. (1955). A.M.A. Arch. Surg., 71. 551.

Franklin, R. H. (1952). Surgery of the Oesophagus. Arnold, London.

Gray. H. K., and Skinner, I. C. (1940). J. thorac. Surg., 10, 220.

Hawthorne, H. R., Frobese, A. S., and Nemir, P. (1956).' Ann. Surg., 144, 653.

- and Nemir, P. (1953). Gastroenterology, 25, 349.

Heller, E. (1914). Mitt. Grenzgeb. Med. Chir., 27, 141.

Johnstone, A. S. (1950). In A Textbook of X-ray Diagnosis, 2 nd ed., edited by S. C. Shanks and P. Kerley, 3, 42. Lewis, London.

Michaud, P., and Latreille, R. (1955). Arch. Mal. Appar. dig., 44, 306.

Turner, G. G. (1946). Injuries and Diseases of the Oesophagus. Cassell, London.

Wangensteen, O. H. (1951). Ann. Surg., 134, 301.

Wooler, G. H. (1948). Thorax, 3, 53.

\section{CARBUTAMIIDE IN JUVENILE DIABETES}

BY

J. M. SMELLIE, O.B.E., T.D., M.D., F.R.C.P. Professor of Paediatrics and Child Health, University of Birmingham

In August, 1956, the British Medical Journal published six articles (Duncan et al., 1956; Wolff et al., 1956; Hunt et al., 1956 ; McKenzie et al., 1956 ; Walker et al., 1956 ; Murray and Wang, 1956) reporting the observations of British workers who had been treating diabetic patients with the hypoglycaemic sulphonamide known as carbutamide (BZ 55). These studies confirmed that the type of patient responsive to this treatment is the middle-aged or elderly diabetic who has never had ketosis or who needs less than 30 units of insulin a day.

The original German reports stated that carbutamide effected no improvement in children suffering from diabetes, and the English literature deals almost exclusively with adults. Chute and Bain (1956) treated five children and found no evidence of a hypoglycaemic effect. Barta (1957) tested the drug in 16 patients between 6 and 13 years of age, and states that the blood-sugar level was not reduced by carbutamide even in full adult doses. On the other hand, Engleson and Lehmann (1956) consider that these preparations are of limited value in juvenile diabetes provided the dosage is very high, but that side-effects are likely to develop.

The mode of action of the so-called hypoglycaemic sulphonamides is still undetermined, but various possibilities have been advanced (Young, 1956 ; Best, 1956)-for example, stimulation of beta cells leading to increased insulin secretion, inhibition of activity of alpha cells, depression of secretion of glucagon, inhibition of insulinase, and the possibility that this sulphonamide may depress an occult infection in the liver or elsewhere which is accelerating the breakdown of insulin. The metabolic investigations of Bastenie et al. (1957) would appear to indicate that sulphonamide treatment induces no increased uptake of glucose by the tissues and the improvement in the diabetes cannot be ascribed to an increase of either secretion or activity of insulin.

The desirability and advantages of a drug that can be given by mouth to control diabetes mellitus, particularly in children, needs no emphasis. Before any such substance can be recommended its efficacy, its safety, and its reliability must be established beyond doubt, it being appreciated in particular that therapy will be lifelong. The authors of the papers in the British Medical Journal already referred to issued a warning that carbutamide should at present be used only under careful hospital supervision, in view of certain complications that were being reported in some cases.

The investigations herein recorded were undertaken to ascertain whether, with a careful selection of cases based on reported experiences with adult diabetics, this oral sulphonamide had any place in the treatment of children. In general the adults who have been treated have been diabetics of long standing, and presumably their beta cells are atrophied and their endogenous insulin-secretion negligible. If carbutamide acts, at least in part, by stimulation of the beta cells, then its antidiabetic action might perhaps be much greater in the young diabetic whose illness is of recent origin and who may therefore still have an appreciable secretion of endogenous insulin. Theoretically, however this substance may act, the recuperative potentialities of a child of 10 years should be many times greater than his adult counterpart of 50 or more, as he has not been subjected to the dietetic and other insults and indiscretions of the latter.

\section{Case 1}

A boy aged $7 \frac{1}{2}$ years developed symptoms of diabetes in June, 1956. On admission to hospital three weeks later the diagnosis was established and he was stabilized on a diet of $220 \mathrm{~g}$. of carbohydrate (with unlimited protein and fat) and 14 units of insulin zinc suspension once daily. He remained well and returned to school.

He was readmitted in October. His diet was then fixed at $210 \mathrm{~g}$. of carbohydrate, and insulin was omitted. A few days later a diurnal blood-sugar curve showed a fasting level of $127 \mathrm{mg} . / 100 \mathrm{ml}$. with a rise to $510 \mathrm{mg} . / 100 \mathrm{ml}$. later in the day, but his urine remained free from acetone. He was then treated with carbutamide for a period of nine days. Fig. 1 records his progress. This shows that, although his

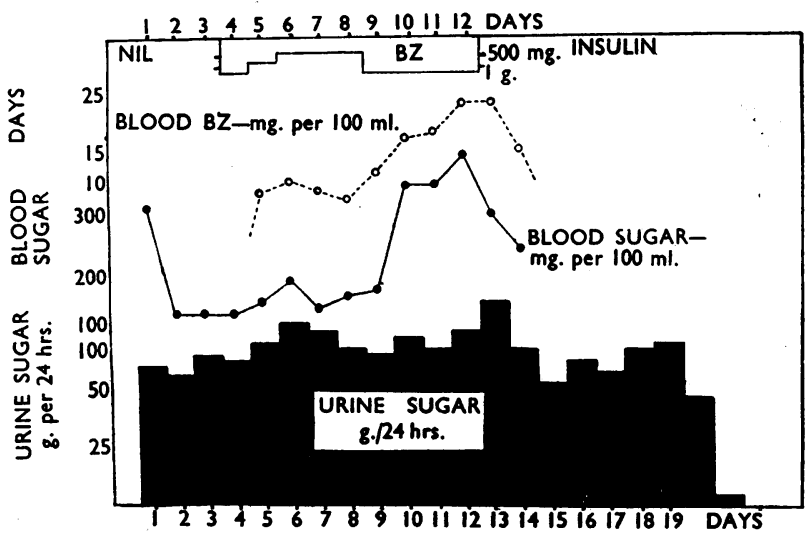

Fig. 1.-Progress and treatment in Case 1. 